Research Article

\title{
Efficacy and safety comparison of topical loteprednol and topical non-steroidal anti-inflammatory drugs in seasonal allergic conjunctivitis: a prospective open label comparative study
}

\author{
Sheshidhar G. Bannale ${ }^{1 *}$, Pundarikaksha $\mathbf{H P}^{2}$, Sowbhagya $\mathrm{HN}^{3}$, Jyothi $\mathbf{R}^{2}$, Vijendra $\mathbf{R}^{2}$
}

\begin{abstract}
${ }^{1}$ Assitant Professor, Department of Pharmacology S.

Nijalingappa Medical College

Bagalkot, India

${ }^{2}$ Department of Pharmacology,

${ }^{3}$ Department of Ophthalmology

KIMS, Bangalore, India
\end{abstract}

Received: 21 March 2016

Accepted: 27 April 2016

*Correspondence to:

Dr. Sheshidhar G. Bannale,

Email: drshashibannale@

yahoo.co.in

Copyright: (C) the author(s), publisher and licensee Medip Academy. This is an openaccess article distributed under the terms of the Creative Commons Attribution NonCommercial License, which permits unrestricted noncommercial use, distribution, and reproduction in any medium, provided the original wrork is nronerly rited

\begin{abstract}
Background: Seasonal allergic conjunctivitis (SAC) one of the most common ocular immunological disorder affecting wide population. Various classes of drugs are been used to control allergic inflammation. Traditionally topical glucocorticoids have been used for SAC. However, repeated and continuous use of steroids is associated with various complications like increase in intraocular pressure, posterior sub capsular cataract, increased susceptibility for infections and delayed wound healing. Hence the current emphasis is to prefer topical NSAIDs as they are free from various steroid related complications. As there is paucity of information regarding the comparative efficacy of topical steroids and NSAIDs, the present study was taken up. The main objective was to study the comparative efficacy and safety of three topical NSAIDs: flurbiprofen, diclofenac, ketorolac and the topical steroid loteprednol, in SAC.
\end{abstract}

Methods: A prospective, comparative study enrolled 40 patients for SAC. All study drugs were instilled 4 times daily for 4 weeks. Patients were assessed for objective and subjective parameters of inflammation at baseline and weekly intervals for 4 weeks using four point scales, and also observed for any side effects. The anti-inflammatory action was assessed by the change in mean scores from basal and at various intervals.

Results: Loteprednol was more effective than the three NSAIDs, only ketorolac comparable to loteprednol in relieving ocular itching. Study drugs showed good safety and tolerability, with only minimal local side effects.

Conclusions: SAC the topical steroid loteprednol was found superior to NSAIDs.

Keywords: SAC, Loteprednol, NSAIDs

\section{INTRODUCTION}

Seasonal Allergic conjunctivitis (SAC) is the most common allergic disorder which affect ocular surface. ${ }^{1,2}$ Itching is the most common symptom of ocular allergy and other symptoms include eyelid swelling, tearing, photophobia, watery discharge, foreign body sensation and pain. ${ }^{3}$ Among the most common allergens that cause conjunctivitis include pollen, dust, air pollution, cosmetics, and medicines. Clinical manifestations of SAC includes type I immunological hypersensitivity reaction leading to release of various chemical mediators, mainly histamine as the principal causative agent of the clinical manifestations, other mediators include tryptase, leukotrienes, prostaglandins, cytokines, chemokines, proteases, growth factors, and adhesion molecules. ${ }^{4,5}$

Allergic conjunctivitis is common in people who have other allergic disorders such as hay fever, asthma and eczema. ${ }^{6}$ Reported studies have shown an incidence of $17 \%$ of patients attending ophthalomology unit in an tertiary care centre includes allergic eye diseases, where as in western world it is from $15-50 \%$.

Quality of life is also affected by patients with SAC, influencing at large on the economic condition of patient and society. ${ }^{1,8}$ 
Treatment option includes various groups of drugs like decongestants, corticosteroids, NSAIDS, mast cell stabilizers, antihistamines and immune modulators. Traditionally topical steroids have been used since several decades because of their powerful antiinflammatory action. However repeated and continuous topical application of steroids is associated with various complications like cataract, (steroid induced) glaucoma, increased susceptibility for infections and delay in wound healing. Hence the current emphasis is on topical nonsteroidal anti-inflammatory drugs (NSAIDs) as they are likely to be free from steroid related complications. There are several NSAIDs currently available for topical application - indomethacin, diclofenac, flurbiprofen and ketorolac. These NSAIDs have been used in the past few years mainly for post-operative ocular inflammation i.e. following cataract extraction and strabismus surgery, and only recently they have been recommended even for nontraumatic inflammation like allergic conjunctivitis. However there are few studies and reports comparing their efficacy, safety and tolerability with that of topical steroids in seasonal allergic conjunctivitis in Indian population and hence the present study is taken up to study the efficacy, safety and tolerability of three topical NSAIDs: flurbiprofen $(0.03 \%)$, diclofenac $(0.1 \%)$ and ketorolac $(0.5 \%)$, in comparison with topical steroid loteprednol $(0.5 \%)$ in seasonal allergic conjunctivitis (SAC).

\section{METHODS}

After obtaining approval and clearance from the institutional ethics committee, 40 patients were included in study at out-patients and in-patients, in the department of ophthalmology, KIMS Hospital and Research Centre, Bangalore, India. Informed consent was obtained from all the patients, In case patient being minor informed consent was obtained from parents/guardians. Selective sample of 40 patients fulfilling the inclusion/exclusion criteria were randomly assigned into 4 groups of 10 in each receiving flurbiprofen, diclofenac, ketorolac, and loteprednol respectively.

\section{Inclusion criteria}

- Patients of all age group with itching of variable severity and seasonal exacerbations.

- Patients with 2-3 attacks in past 2 year duration.

- Patients who had both palpebral and bulbar manifestations.

- Willingness to give informed consent.

\section{Exclusion criteria}

- Patients who also have acute systemic allergic manifestations like bronchial asthma, hay fever and allergic rhinitis.

- Patients with large lesions (giant papillae), which need surgical treatment.

- Lesions involving cornea.
- Patients with known/suspected allergy to NSAIDs.

- Patients who have used NSAIDs in the past 2 weeks.

After obtaining informed consent, a detailed clinical history of the present illness and significant past history, including the present or past drug history was recorded. The procedures which were followed during the study were in accordance with the ethical standards which were laid down by Indian council of medical research (ICMR)'s guidelines for biomedical research on human subjects (2006) and with the declaration of Helsinki. General physical examination was done to assess vital signs and systemic examination to assess all systemic function. Ocular examination was done using torch light and slit lamp. After confirming diagnosis and study procedure was explained in detail. Patients are randomly assigned to one of the four groups i.e. group I- diclofenac $(0.1 \%)$, group II- flurbiprofen $(0.03 \%)$, Group IIIketorolac $(0.5 \%)$ and group IV- loteprednol $(0.5 \%)$. Study medications were instilled into the affected eyes 4 times daily and continued for 4 weeks. Clinical signs and symptoms were assessed at baseline and at intervals of 7 days for 4 weeks. The parameters assessed were ocular itching, hyperaemia and regression of papillary lesions, by grading on a 4-point scale (none-severe) as mentioned below. ${ }^{9}$

\section{Ocular itching}

- Grade 0: None

- Grade 1: Intermittent tickling sensation, involving more than corner of eye

- Grade 2: Mild, continuous itch without desire to rub

- Grade 3: Severe itch with desire to rub

\section{Hyperaemia}

- Grade 0: None

- Grade 1: Mild, slightly dilated blood vessels, pink in colour, quadrantal

- Grade 2: Moderate, more apparent vascular dilation, more intensely coloured, involving most of vessel bed

- Grade 3: Severe, numerous and obvious dilated blood vessels, deep red colour

\section{Papillary lesions}

- Grade 0: None

- Grade 1: Mild-fine papillae, size $<1 \mathrm{~mm}$

- Grade 2: Moderate-papillae size 1-2 mm

- Grade 3: Severe-thick hypertrophied limbal/palpebral papillae, size $>2 \mathrm{~mm}$.

\section{Statistical methods involved}

The data obtained is summarized using mean, median, standard deviation and range for continuous variables. Chi-square and 2x4, 3x4, 4x4 Fisher exact test has been used to find the significance of study parameters on 
categorical scale between two or more groups. ANOVA has been used to find the homogeneity of parameters on continuous scale. To compare the means of samples Kruskal Wallis test (non-parametric) has been used.

\section{RESULTS}

There was no statistically significant difference between the groups $(\mathrm{P}=0.220)$ with respect to age and gender $(\mathrm{P}=0.678)$ at baseline as depicted in (Table 1 and 2$)$.

Table 1: Age distribution.

\begin{tabular}{|c|c|c|c|c|c|c|c|c|c|c|}
\hline \multirow{2}{*}{$\begin{array}{l}\text { Age } \\
\text { (years) }\end{array}$} & \multicolumn{2}{|c|}{$\begin{array}{l}\text { Group I } \\
\text { diclofenac }\end{array}$} & \multicolumn{2}{|c|}{$\begin{array}{l}\text { Group II } \\
\text { flurbiprofen }\end{array}$} & \multicolumn{2}{|c|}{$\begin{array}{l}\text { Group III } \\
\text { ketorolac }\end{array}$} & \multicolumn{2}{|c|}{$\begin{array}{l}\text { Group IV } \\
\text { loteprednol }\end{array}$} & \multicolumn{2}{|c|}{ Pooled } \\
\hline & No & $\%$ & No & $\%$ & No & $\%$ & No & $\%$ & No & $\%$ \\
\hline $11-15$ & 4 & 40.0 & 5 & 50.0 & 3 & 30.0 & 5 & 50.0 & 17 & 42.5 \\
\hline $16-20$ & 3 & 30.0 & 3 & 30.0 & 3 & 30.0 & 4 & 40.0 & 13 & 32.5 \\
\hline $21-25$ & 2 & 20.0 & 2 & 20.0 & 3 & 30.0 & 1 & 10.0 & 8 & 20 \\
\hline $25-30$ & 1 & 10.0 & 0 & 0 & 1 & 10.0 & 0 & 0 & 2 & 5 \\
\hline Total & 10 & 100.0 & 10 & 100.0 & \multirow{2}{*}{\multicolumn{2}{|c|}{$\begin{array}{l}100.0 \\
4.59\end{array}$}} & \multirow{2}{*}{\multicolumn{2}{|c|}{$\begin{array}{l}10 \quad 100.0 \\
15.90 \pm 3.04\end{array}$}} & 40 & 100 \\
\hline Mean \pm SI & \multicolumn{2}{|c|}{$16.80 \pm 5.20$} & \multicolumn{2}{|c|}{$15.80 \pm 3.39$} & & & & & \multicolumn{2}{|c|}{$16.95 \pm 4.24$} \\
\hline
\end{tabular}

Table 2: Gender distribution.

\begin{tabular}{|lllllllllll|}
\multirow{2}{*}{ Gender } & \multicolumn{2}{l}{$\begin{array}{l}\text { Group I } \\
\text { diclofenac }\end{array}$} & \multicolumn{2}{l}{$\begin{array}{l}\text { Group II } \\
\text { flurbiprofen }\end{array}$} & \multicolumn{2}{l}{$\begin{array}{l}\text { Group III } \\
\text { ketorolac }\end{array}$} & \multicolumn{2}{l}{$\begin{array}{l}\text { Group IV } \\
\text { loteprednol }\end{array}$} & \multicolumn{2}{l|}{ Pooled } \\
& No & \% & No & \% & No & \% & No & \% & No & \% \\
\hline Male & 4 & 40.0 & 6 & 60.0 & 7 & 70.0 & 6 & 60.0 & 23 & 57.5 \\
\hline Female & 6 & 60.0 & 4 & 40.0 & 3 & 30.0 & 4 & 40.0 & 17 & 42.5 \\
\hline Total & 10 & 100.0 & 10 & 100.0 & 10 & 100.0 & 10 & 100.0 & 40 & 100 \\
\hline
\end{tabular}

Table 3: Mean scores: objective and subjective parameters.

\begin{tabular}{|c|c|c|c|c|c|}
\hline & $\begin{array}{l}\text { Group I } \\
\text { diclofenac }\end{array}$ & $\begin{array}{l}\text { Group II } \\
\text { flurbiprofen }\end{array}$ & $\begin{array}{l}\text { Group II } \\
\text { ketorolac }\end{array}$ & $\begin{array}{l}\text { Group IV } \\
\text { loteprednol }\end{array}$ & P-value \\
\hline \multicolumn{6}{|c|}{ Conjunctival hyperaemia } \\
\hline Visit 0 & $2.0 \pm 0$ & $1.9 \pm 0.32$ & $1.9 \pm 0.32$ & $2.1 \pm 0.32$ & 0.310 \\
\hline Visit 1 & $2.0 \pm 0$ & $1.9 \pm 0.32$ & $1.8 \pm 0.42$ & $1.2 \pm 0.42$ & $<0.001 * *$ \\
\hline Visit 2 & $2.0 \pm 0$ & $1.8 \pm 0.42$ & $1.4 \pm 0.52$ & $0.6 \pm 0.52$ & $<0.001 * *$ \\
\hline Visit 3 & $1.2 \pm 0.42$ & $1.4 \pm 0.52$ & $1.0 \pm 0$ & $0.1 \pm 0.32$ & $<0.001 * *$ \\
\hline Visit 4 & $1.0 \pm 0$ & $1 \pm 0$ & $0.6 \pm 0.52$ & $0 \pm 0$ & $<0.001 * *$ \\
\hline \multicolumn{6}{|c|}{ Papillary reaction } \\
\hline Visit 0 & $1.6 \pm 0.52$ & $1.8 \pm 0.42$ & $1.8 \pm 0.42$ & $1.8 \pm 0.42$ & 0.668 \\
\hline Visit 1 & $1.6 \pm 0.52$ & $1.8 \pm 0.42$ & $1.8 \pm 0.42$ & $1.1 \pm 0.32$ & $0.004 * *$ \\
\hline Visit 2 & $1.6 \pm 0.52$ & $1.8 \pm 0.42$ & $1.5 \pm 0.53$ & $0.9 \pm 0.32$ & $0.002 * *$ \\
\hline Visit 3 & $1.6 \pm 0.52$ & $1.6 \pm 0.52$ & $1 \pm 0$ & $0.2 \pm 0.42$ & $<0.001 * *$ \\
\hline Visit 4 & $1.6 \pm 0.52$ & $1.3 \pm 0.48$ & $1 \pm 0$ & $0.1 \pm 0.32$ & $<0.001 * *$ \\
\hline \multicolumn{6}{|c|}{ Ocular itching } \\
\hline Visit 0 & $2.2 \pm 0.42$ & $2.2 \pm 0.42$ & $2.1 \pm 0.32$ & $1.8 \pm 0.42$ & 0.121 \\
\hline Visit 1 & $1.9 \pm 0.32$ & $2.1 \pm 0.32$ & $1.3 \pm 0.48$ & $1.1 \pm 0.32$ & $<0.001 * *$ \\
\hline Visit 2 & $1.8 \pm 0.42$ & $1.8 \pm 0.42$ & $0.9 \pm 0.32$ & $0.5 \pm 0.53$ & $<0.001 * *$ \\
\hline Visit 3 & $1.8 \pm 0.42$ & $1.3 \pm 0.48$ & $0.3 \pm 0.48$ & $0 \pm 0$ & $<0.001 * *$ \\
\hline Visit 4 & $1.1 \pm 0.32$ & $1.2 \pm 0.42$ & $0.1 \pm 0.32$ & $0 \pm 0$ & $<0.001 * *$ \\
\hline
\end{tabular}

The effect of study drugs on the objective parameters of SAC are summarized in Table 3. There was no statistically significant difference at baseline between the groups, all were comparable. However significant difference observed during subsequent visits. Conjunctival hyperaemia was graded on a four point scale 
0-3. Most of the patients (92.5\%) had grade-2 hyperaemia, whereas grade- 1 was seen in 2 patients and grade- 3 in only one patient. Statistically significant difference in the drug effects among the groups was observed at visit 2, 3 and 4 . The reversal to grade 0 was seen in all the patients $(100 \%)$ in loteprednol group and only 4 patients $(40 \%)$ in ketorolac group at visit 4 , whereas in diclofenac and flurbiprofen groups grade 1 hyperemia persisted in all patients at the end of 4 weeks.

The study subjects had only grade $1(25 \%)$ and grade 2 $(75 \%)$ papillary reaction at visit 0 (basal) and there was no statistically significant difference between the groups. Resolution started much faster in loteprednol group and complete resolution to grade 0 was seen in $90 \%$ of the patients after 4 weeks, whereas in other groups none of the patients showed resolution to grade $0 ; 70 \%$ of the patients in the flurbiprofen and all patients in the ketorolac group showed reversal to grade 1 , whereas in the diclofenac group there was no improvement from basal value at the end of 4 weeks. The difference between the groups was significant at visit 1, 2, 3 and 4.

Subjective parameter, ocular itching at baseline was, $85 \%$ patients had the grade 2 , only 2 patients $(5 \%)$ had grade 1 and 4 patients $(10 \%)$ had grade 3 itching at the basal and the difference among the groups was not statistically significant. Loteprednol showed rapid improvement, and complete disappearance of itching was seen within 3 weeks. In ketorolac group $90 \%$ of the subjects were completely free from itching after 4 weeks. However grade 1 and grade 2 itching persisted in the other 2 groups (flurbiprofen and diclofenac) even at the end of 4 weeks. The difference between the groups was statistically significant at visit 1, 2 and 3 .

\section{DISCUSSION}

Ocular inflammation may occur due to various causes traumatic and non-traumatic. Traumatic may be surgical or non-surgical. Non-traumatic causes include infective, immunological, chemical, radiological etc. Allergic conjunctivitis is one of the most common nontraumatic extraocular inflammatory condition and includes seasonal allergic conjunctivitis (SAC)/vernal keratoconjunctivitis (VKC)/spring catarrh, perennial allergic conjunctivitis (PAC), atopic keratoconjunctivitis (AKC) and drug induced allergic conjunctivitis (DIAC). ${ }^{10}$ The treatment options include topical antihistaminics, mast cell stabilizers, steroids and NSAIDs. Though the topical steroids have been widely used, because of their limitations, may not be the preferred option except for severe or refractory forms of allergic conjunctivitis. The potential advantages of topical NSAIDs over steroids may place them as better option even in allergic conjunctivitis. Among the topical NSAIDs only ketorolac is currently approved for this purpose. ${ }^{10,11}$

NSAIDs act by reducing the PG biosynthesis due to inhibition of cyclo-oxygenace enzyme whereas steroidal agents act at multiple levels, hence both these classes of drugs are useful. ${ }^{12}$

The currently available topical NSAIDs as eye drops include- flurbiprofen $(0.03 \%)$, diclofenac $(0.1 \%)$, ketorolac $(0.5 \%)$, indomethacin $(1 \%)$. The first three of them have good ocular penetration whereas indomethacin has limited penetration. Systemic absorption of all topical NSAIDs is minimal. ${ }^{11}$ All of them have shown good ocular tolerability other than transient discomfort (stinging) after instillation. ${ }^{13}$

The topical steroids (glucocorticoids) available as eye drops include betamethasone $(0.1 \%)$, dexamethasone $(0.1 \%)$, prednisolone $(0.1 \%$ and $1 \%)$, fluoromethalone $(0.1 \%)$ and loteprednol $(0.5 \%)$. Loteprednol which belongs to the latest generation of topical steroids is claimed to be a "soft steroid" and therefore less likely to produce the various steroid-related complications, is recently marketed in India. ${ }^{4}$ However, there are inadequate data regarding its efficacy and safety in Indian population hence this study was taken up.

The tabulated values may be considered as suggestive of the overall efficacy and onset of action of drugs in SAC. Loteprednol was significantly more effective in suppressing the various parameters at all stages of observation. Among the three NSAIDs, ketorolac was most effective showing a comparable efficacy with loteprednol in relieving ocular itching, moderate efficacy in reducing conjunctival hyperaemia but was less effective in reversing papillary reaction. Diclofenac and flurbiprofen showed comparable efficacy in reducing conjunctival hyperemia and ocular itching but were significantly less effective compared to other 2 drugs (Figure 1).

The adverse effects of the study drugs are recorded in (Figure 2). They were only mild and transient local effects reported at visit 1 and disappeared subsequently indicating good tolerability of the drugs with continued administration. Though the difference was not statistically significant between the groups, loteprednol appeared to have better tolerability as it produced stinging in only 2 patients. There were no other sequelae and no systemic effects were observed.

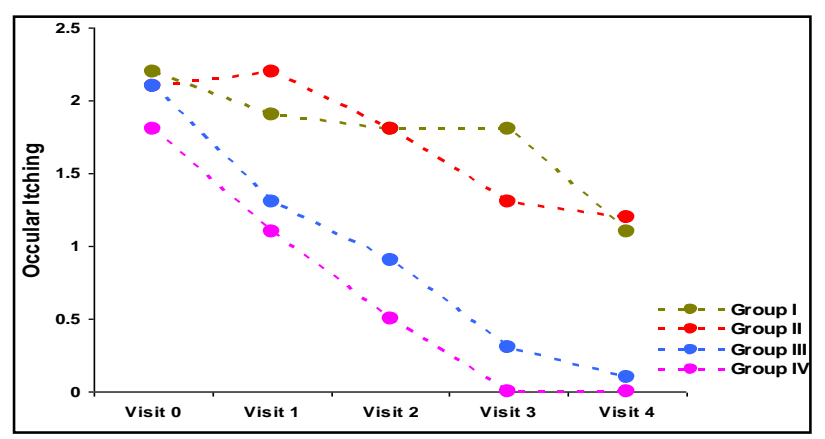

Figure 1: Ocular itching at baseline and follow-up. 


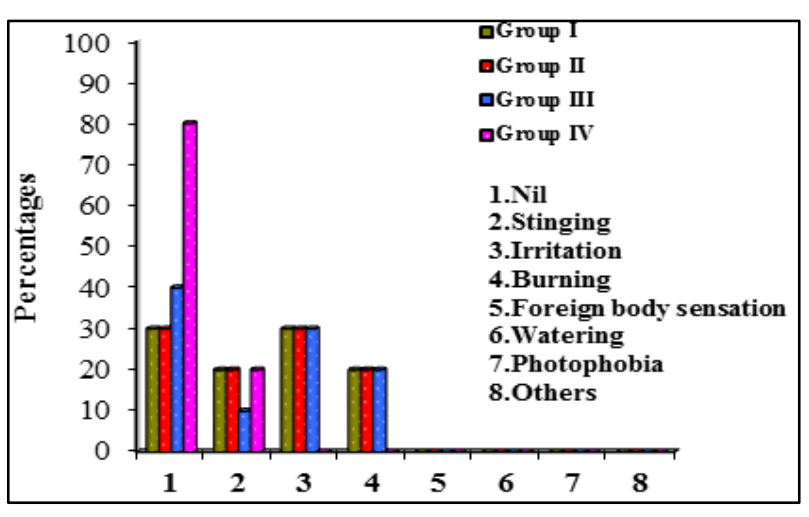

Figure 2: Side effects experienced by participants in all groups.

The SAC is a recurrent and chronic allergic inflammatory response to known or unknown allergen, usually occurring in younger age group children and adolescents. The allergic inflammation in SAC mainly involves the role of mast cell derived chemical mediators like histamine. For SAC, conjunctival hyperemia and papillary reaction were considered as objective parameters and ocular itching as the subjective parameter. Conjunctival hyperemia is a vascular response, whereas papillary reaction as a cellular response to allergic inflammation. In reducing conjunctival hyperemia and papillary reaction, loteprednol was distinctly more effective than other three drugs at all the visits, whereas in relieving ocular itching only ketorolac was almost comparable to loteprednol both in the onset of action and maximal efficacy.

Diclofenac had virtually no effect on resolving papillary reaction. Thus loteprednol was found to be most effective in suppressing or relieving all the parameters of SAC. Among the three NSAIDs, ketorolac was found superior to other two NSAIDs particularly in relieving ocular itching. Though all the study drugs showed good tolerability with minimal local side effects, loteprednol seemed to have a slightly better tolerability.

The results and observations of present study are indicative of loteprednol was distinctly superior to the other three NSAIDs. This difference may be because of different mechanisms and mediators involved in these two different types of inflammation, prostaglandins (PGs) being the primary mediators in post-operative inflammation and mast cell derived chemical mediators playing a major role in SAC.

The primary mechanism of action of NSAIDs is inhibition of PG biosynthesis, whereas the steroids have a more versatile anti-inflammatory action with a diverse and wide range of mechanisms, being particularly effective in suppressing allergic inflammatory response. In allergic conjunctivitis diclofenac and ketorolac were similar in relieving the symptoms particularly itching, and some studies have shown superiority of ketorolac in relieving ocular itching. ${ }^{14,4,9,15}$ The efficacy of topical NSAIDs particularly ketorolac in relieving ocular itching is probably related to the decreased synthesis of pruritogenic PGs-PGE-2 and PGI-2. ${ }^{4}$ In several other studies ketorolac was found to be most effective among the topical NSAIDs in relieving ocular symptoms, particularly itching. Ketorolac is the only topical NSAIDs approved for SAC in many countries. ${ }^{4}$

However, it was less effective in relieving conjunctival hyperemia and papillary reactions, which was consistent with the observations of the present study. Because of their lack of various steroid related complications like increased Intraocular pressure, Posterior sub-capsular cataract, increased susceptibility to infections and delay in wound healing, topical NSAIDs may be preferred to steroids in various ocular inflammation, and the steroids generally reserved for more severe and resistant inflammation.

However, topical NSAIDs may be used in very early stage, milder form of allergic conjunctivitis but steroids are more efficacious in management of SAC because of their greater efficacy. Among the NSAIDs, ketorolac can be considered as alternative to topical steroid particularly in relieving ocular itching. Loteprednol, the soft steroid may be preferable to the conventional topical steroids in allergic ocular inflammation as it is rapidly hydrolyzed to its inactive metabolites in the corneal and intraocular tissues and hence free from various steroid related ocular complications. ${ }^{4,16-19}$

\section{CONCLUSION}

Loteprednol has shown more efficacy than the three NSAID's. Small sample size the main limitation of this study, hence further more elaborate studies involving larger number of patients and in various other types of ocular inflammatory conditions and also considering combinations with other classes of drugs may be worth undertaking.

\section{ACKNOWLEDGEMENTS}

The authors would like to acknowledge the statistical assistance given by Dr. K. P. Suresh from National Institute of Animal Nutrition and Physiology (NIANP), Bangalore, India.

\section{Funding: No funding sources Conflict of interest: None declared \\ Ethical approval: The study was approved by the Institutional Ethics Committee}

\section{REFERENCES}

1. Alexander M, Berger W, Buchholz P. The reliability, validity, and preliminary responsiveness of the eye allergy patient impact questionnaire(EAPIQ). Health Qual Life Outcomes. 2005;3:67.

2. Singh K, Bielory L. Epidemiology of ocular allergy symptoms in United states adults (1988-1994). 
Proceedings of American allergy asthma and immunology annual meeting, Philadelphia. Ann Allergy Asthma Immunol. 2007;98:22.

3. Rosa ML, Lionetti E, Reibaldi M, Russo A, Longo A, Leonordi S, et al Allergic conjunctivitis: a comprehensive review of the literature. Italian Journal of Pediatrics. 2013;39:18.

4. Bielory L, Friedlaender MH. Allergic Conjunctivitis. Immunol Allergy Clin North Am. 2008;28:43-58.

5. Ackerman S, Smith LM, and Gomes PJ. Ocular itch associated with allergic conjunctivitis: latest evidence and clinical management Ther Adv Chronic Dis. 2016;7(1):52-67.

6. Keziah N. Malu. Allergic conjunctivitis in JosNigeria. Niger Med J. 2014;55(2):166-70.

7. Biswas J, Saha I, Debabrata D, Bandyopadhyay S, Ray B, Biswas G. Ocular morbidity among children at a tertiary eye care hospital in Kolkata, West Bengal. Indian J Public Health. 2012;56(4):293-6.

8. Smith AF, Pitt AD, Rodruiguez AE, Alio JL, Marti $\mathrm{N}$. The economic and quality of life impact of seasonal allergic conjunctivitis. Ophthalmic epidemiol. 2005; 12:233-42.

9. Yaylali V, demirlenk I, Tatlipinar S, Ozbay D, Esme A, Yildirim C, et al. Comparative study of $0.1 \%$ olopatadine hydrochloride and $0.5 \%$ ketorolac tromethamine in the treatment of seasonal allergic conjunctivitis. Acta Ophthalmologica Scandinavica. 2003;81(4):378-2.

10. Chensue SW, Ward PA. Inflammation. In: Anderson's pathology. 10th ed. Damjanov I, Linder J.editors. New York: Anne S Patterson; 1996:387415.

11. Larsen GL, Henson PM. Mediators of Inflammation. Annual review of Immunology. 1983;1:335-59.
12. Edward L, Hower Jr. Basic mechanism in pathology. Inflammation. In: Ophthalmic Pathology an Atlas and Textbook. Spencer WH, Font RL, Green WR, Howes EL, Jakobiec FA, Zimmerman LE. $3^{\text {rd }}$ edition. Philadelphia: WB Saunder Company;1996:1-108.

13. Burke A, Smyth E, Fitzgerald GA. Analgesic antipyretic agents. In: Goodman and Gillman's Pharmacological Basis of Therapeutics, 11th ed. Brunton LL editor. New Delhi: McGrew Hill; 2006:671-716.

14. Joseph Colin. The role of NSAIDs in the management of postoperative inflammation. Drugs. 2007;67(9):1291-308.

15. Swamy BN, Chilov M, McClellan K, Petsoglou C. Topical Non-steroidal anti-inflammatory drugs in allergic conjunctivitis, meta-analysis of randomized trial data. Ophthalmic Epidemiology. 2007;14:311-9.

16. Pavesion CE, Decory HH. Treatment of ocular inflammatory conditions with loteprednol etabonate. British Journal of Ophthalmology. 2008;92:455-9.

17. Awan MA, Agarwal PK, Watson DG, McGhee Charles NJ, Dutton GN. Penetration of topical and subconjunctival corticosteroids into human aqueous humor and its therapeutic significance. British Journal of Ophthalmology. 2009;33:708-13.

18. Noble S, Goa KL. Loteprednol etabonate Clinical potential in the management of ocular inflammation. Biodrugs. 1998;10(4):329-39.

19. Ilyas H, Slonium CB, Braswell GR, Favetta JR, Schulman M. Long-term safety of loteprednol etabonate $0.2 \%$ in the treatment of seasonal and perennial allergic conjunctivitis. Journal of Eye and Contact Lens. 2004;30(1):10-3.

Cite this article as: Bannale SG, Pundarikaksha HP, Sowbhagya HN, Jyothi R, Vijendra R. Efficacy and safety comparison of topical loteprednol and topical non-steroidal anti-inflammatory drugs in seasonal allergic conjunctivitis: a prospective open label comparative study. Int J Basic Clin Pharmacol 2016;5:956-61. 